Research Article

\title{
The Use of Limestone Sand for the Seismic Base Isolation of Structures
}

\author{
Ivan Banović $(\mathbb{D}$, Jure Radnić, Nikola Grgić $(\mathbb{D}$, and Domagoj Matešan \\ Faculty of Civil Engineering, Architecture and Geodesy, University of Split, Matice Hrvatske 15, 21000 Split, Croatia \\ Correspondence should be addressed to Nikola Grgić; nikola.grgic@gradst.hr
}

Received 19 March 2018; Revised 11 June 2018; Accepted 27 June 2018; Published 1 August 2018

Academic Editor: Evangelos J. Sapountzakis

Copyright (C) 2018 Ivan Banović et al. This is an open access article distributed under the Creative Commons Attribution License, which permits unrestricted use, distribution, and reproduction in any medium, provided the original work is properly cited.

\begin{abstract}
The possibility of the use of a layer of natural material under foundations for seismic base isolation was investigated. The dissipation of seismic energy of a low-cost natural material with adequate thickness, bearing capacity, and lateral and vertical stiffness, which can serve as an optimal solution for seismic base isolation under the foundations of many structures, was tested. This paper presents the results of a brief experimental study to determine the effectiveness of ordinary limestone sand under the foundation of a cantilever concrete column to increase its seismic resistance. The behavior of small-scale columns with three substrates below the foundation (rigid base, the thin layer of limestone sand, and the thick layer of limestone sand) was investigated by the shake table. The column was exposed to a set of horizontal base accelerations until structure collapse. It was concluded that a layer of limestone sand of appropriate thickness and compressibility can serve as the means a seismic base isolation. The nonlinear numerical model for the dynamic analysis of planar concrete structures coupled with soil is briefly presented and verified by the performed experimental tests.
\end{abstract}

\section{Introduction}

Earthquakes typically occur when stresses within the earth's crust exceed the strength of the rock, thus causing rock breakage and slip along a fault. The released energy is carried as seismic waves that travel outward in all directions from the initial point of rupture or focus. The seismic waves are reflected and refracted in the earth's crust and at the surface, thereby losing energy with distance as they travel away from the focus. High-frequency seismic waves yield rapid expansion of ground vibrations, whereas low-frequency waves yield a less-rapid expansion and cause ground motions similar to those of sea waves $[1,2]$.

The frequency of seismic waves is very important in determining the nature of the damage to buildings. An earthquake has dominant frequencies that depend on its power, type of fault rupture, distance from the epicenter, geological conditions, and soil characteristics. The dominant natural frequency of vibration of a structure depends on the overall structural characteristics and the soil-structure interaction. If the dominant frequency of earthquake ground shaking is close to the dominant natural frequency of vibration of the structure, then the amplification of waves (resonance) can increase the amount of damage to the structure. Rigid structures are most vulnerable to strong, high-frequency seismic waves. High-frequency waves are strongest near the epicenter but rapidly dissipate as they move outward. High-rise and most deformable structures are the most vulnerable to strong, long duration, lowfrequency waves. Low-frequency waves, which dissipate much more slowly than high-frequency waves, may cause damage at great distances from the epicenter $[1,2]$.

In traditional design and calculation of new structures, as well in renovation of existing, the concept in which the seismic ground acceleration is directly applied to the structure is adopted. Thereby, appropriate codes for seismic analysis of structures are used. To achieve a sufficient level of safety of structures, such an approach often results in buildings of high cost.

In recent decades, the technique increasingly used was seismic base isolation, by which the incoming earthquake ground motion (acceleration) is attenuated before its 
transfer to the structure. Seismic isolation is a technique that has been used around the world to protect building structures, nonstructural components, and the contents of buildings from the damaging effects of earthquake ground shaking. In the base isolation technique approach, the structure is essentially decoupled from the earthquake ground motion by providing separate isolation devices between the structure and the base. The main concept of base isolation is to shift the fundamental period of the structure out of the range of the dominant frequencies of expected earthquakes to reduce the seismic forces on the structure. The consequence of using this concept is the increase of the structure displacements, which must be controlled and limited.

All of the base isolation systems have certain features in common; for example, they exhibit flexibility and have a high energy absorbing capacity. These base isolation systems are mainly categorized into three types: (i) passive base isolation techniques, (ii) hybrid base isolation techniques with semiactive devices, and (iii) hybrid base isolation techniques with passive energy dissipaters. These systems are not considered here. Some detailed information on modern techniques of hybrid passive and active seismic isolation can be found in $[3,4]$. A review of the literature on the theoretical aspects of seismic isolation is given in [5]. The theoretical underpinning of seismic base isolation, which has been firmly established, and the technology that has been verified by extensive experimental work over the past decades are given in [6]. The limits of the applicability of equivalent linear analysis in response to ground motions that can lead to large displacements were investigated in [7]. The "almost lifted structure concept" base isolation system, which was investigated on a two-component shaking table at the Institute of Earthquake Engineering and Engineering Seismology (IZIIS) facility, is shown in [8]. To investigate possible improvements on the design of isolated structures, an extensive research program was conducted at the Pacific Earthquake Engineering Research Center (PEER) [9]. The application of passive seismic isolation for buildings that was primarily practiced in the United States is discussed in [10]. The analysis of an innovative earthquake protection method by placing rubber-soil mixtures (RSMs) around the foundation of structures to absorb seismic energy based on shaking table experimental tests is presented in [11] and based on parametric numerical study in [12].

The devices used in practice are of different complexities, efficiencies, and costs. Unfortunately, the use of such devices is sometimes not economical. In particular, the cost of the used devices sometimes exceeds the savings enabled by the reduction of seismic forces of the structure. A small number of embedded devices have been tested on actual strong earthquakes, while a large number of these devices had not yet been exposed to a strong earthquake, and their actual effectiveness is unknown. Unfortunately, to date, no such device has a life span equal to or greater than the life of a structure, free from the effects of environment and fire and free from maintenance.

For the purpose of broad practical application, such systems of seismic base isolation which are sufficiently efficient, economical, simply to fabricate, safe from the effects of the environment and fire, and easy to maintain are preferred. It is believed that one such solution for many buildings is a layer of adequate natural material placed under the foundation with adequate thickness, bearing capacity, and shear and vertical stiffness, along with the ability to dissipate earthquake energy. Such materials should retain their main mechanical properties over the projected life of the building.

Figure 1 shows a stiff building based directly on rigid ground (a) and based indirectly through a layer of natural material that acts as a seismic isolator (b). As dynamic interaction of the soil-structure coupled system occurs during an earthquake, it is reasonable to expect that the foundation of a building, according to Figure 1(b), can provide higher safety and bearing capacity of the building during an earthquake with higher dominant frequencies. First, in any case, the type of expected ground motions for use in the analysis on respective location must be determined; that is, the dominant frequencies of expected earthquakes, ground motion intensity, and spectral shape are crucial [13]. Next, the optimal natural material for the layer under the foundation acting as a seismic isolator should be determined. Currently, to the author's knowledge, there are very few studies related to the use of natural materials for seismic base isolation of buildings [14-16].

This paper presents the results of a brief experimental study to determine the effectiveness of limestone sand under the foundation of a cantilever concrete column to increase its seismic resistance. The main purpose of this paper is to confirm that the application of one common natural material under the foundation of the cantilever concrete column can increase its bearing capacity and safety during an earthquake. Namely, even decades ago, many restorers of historical buildings suspected that use of a layer of natural stone material under foundation was used not only to increase the soil's bearing capacity but also to help reduce the earthquake forces on the building. This was a motive to check whether a layer of sand below the foundation of the building could reduce earthquake forces.

As the tested structure is fairly soft, the greater efficiency of this approach for seismic base isolation is expected for stiff structures.

\section{Shake Table Testing of Cantilever Concrete Columns with a Foundation on Different Substrates}

The behavior of small-scale cantilever concrete columns with three different substrates below the foundation (Figure 2) was experimentally investigated using a shake table at the University of Split, Croatia. The foundation of the column is placed on a shake table according to each of the following conditions: (i) fixed to the shake table (column C1), (ii) over a $20 \mathrm{~mm}$ thick layer of limestone sand (column C2), and (iii) over a $100 \mathrm{~mm}$ thick layer of limestone sand (column C3). The column is $1080 \mathrm{~mm}$ in height (slenderness approximately 75), with a square cross section of $100 \mathrm{~mm} \times 100 \mathrm{~mm}$. The column is rigidly constrained at the foundation with 


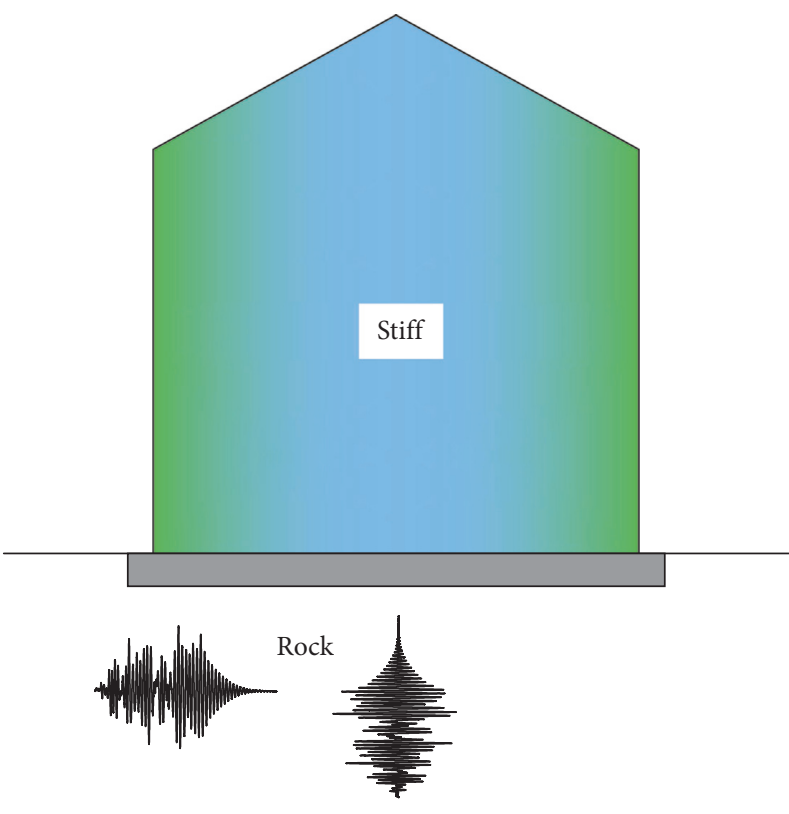

(a)

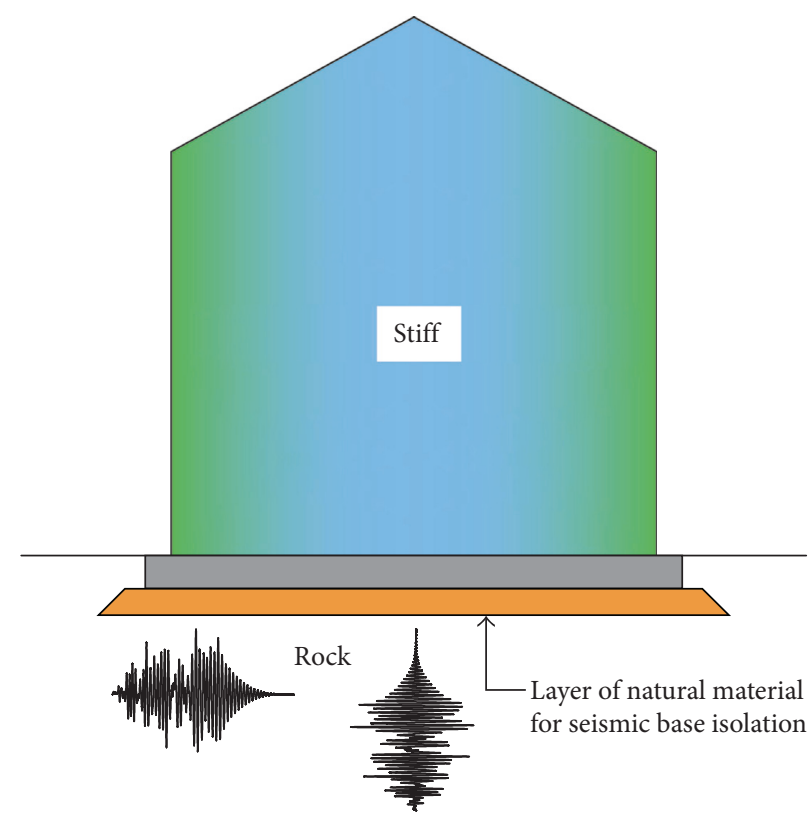

(b)

FIgURE 1: Two variants of foundations of stiff buildings on rigid soil.
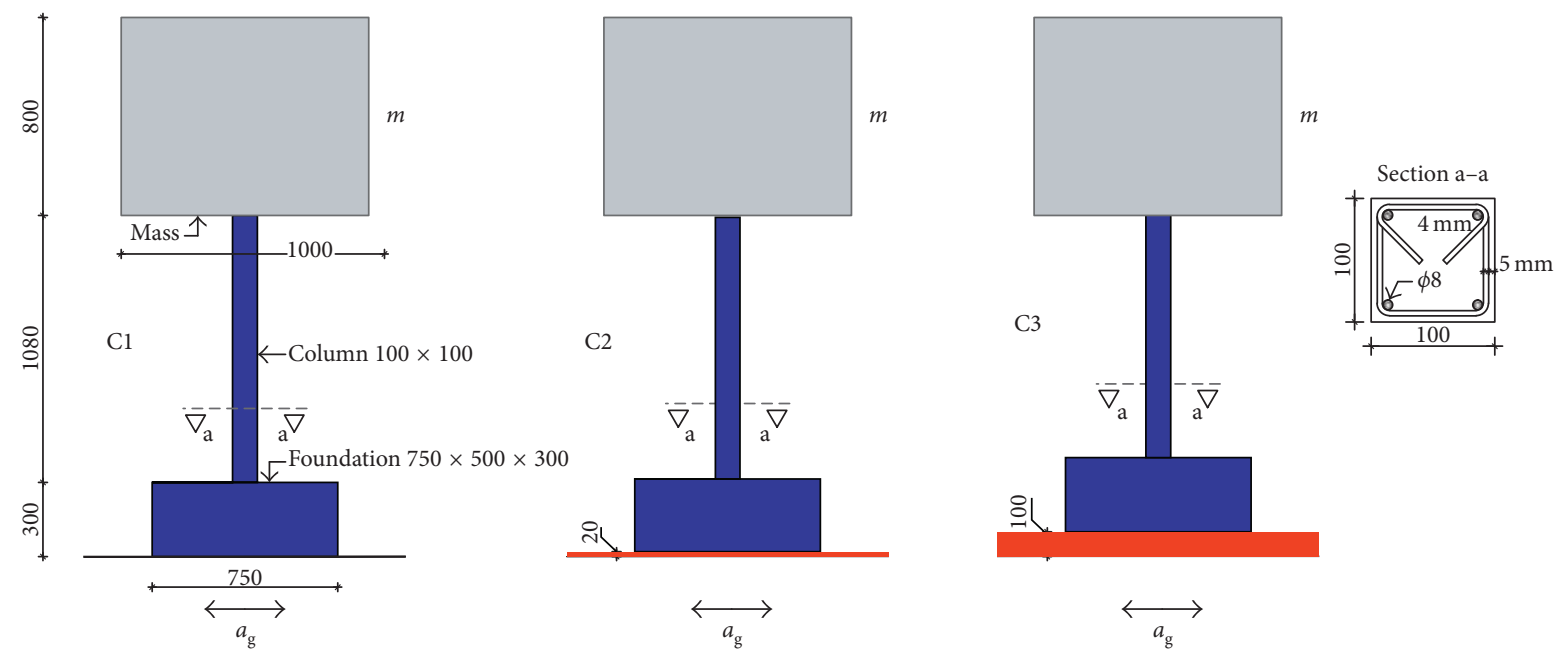

Figure 2: Basic data of the tested column.

a length of $750 \mathrm{~mm}$, a width of $500 \mathrm{~mm}$, and a height of $300 \mathrm{~mm}$. A mass of 2 tons is placed on the top of the column, comprised of a concrete block of size of $1000 \mathrm{~mm} \times$ $1000 \mathrm{~mm} \times 800 \mathrm{~mm}$. The center of mass coincides with the axis of the column; that is, the column was a centrically loaded due to gravity load.

The column and foundation were made of concrete with limestone aggregate, with a maximal grain size of $8 \mathrm{~mm}$. The compressive strength of the concrete was $37.2 \mathrm{MPa}$ and Young's modulus was $33.2 \mathrm{GPa}$. The flexural tensile strength of concrete was $3.9 \mathrm{MPa}$. The column was reinforced with vertical bars $4 \Phi 8 \mathrm{~mm}$ (As $=201.1 \mathrm{~mm}^{2}$, i.e., $2 \%$ of the concrete cross-sectional area) and $\Phi 4.2 \mathrm{~mm}$ stirrups at a spacing of $50 \mathrm{~mm}$. The ultimate strength of the steel was $653 \mathrm{MPa}$, and Young's modulus was $205 \mathrm{GPa}$. The foundation was reinforced with longitudinal bars $4 \Phi 10 \mathrm{~mm}$ in the upper and bottom zones and with stirrups at a spacing of $100 \mathrm{~mm}$. Only slightly compacted dry limestone sand below the foundation of columns $\mathrm{C} 2$ and $\mathrm{C} 3$, with a grain size in the range of $0-4 \mathrm{~mm}$, was used as the seismic isolator.

The tested structures were exposed to a set of repeated horizontal base accelerations of artificial accelerograms created to match the elastic response spectra according to EN 1998 (EC 8) for type 1 and soil type A (Figure 3). Herein, $T$ is the natural period of the elastic single degreeof-freedom system, and $S_{\mathrm{a}}$ is the spectral acceleration. Artificial accelerograms were obtained by the software SIMQKE, generated as a superposition of sinus functions 


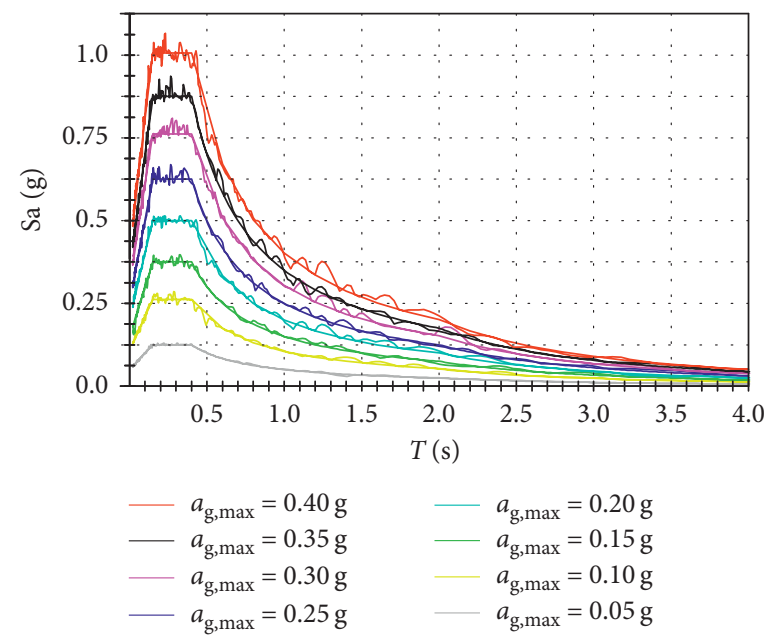

(a)
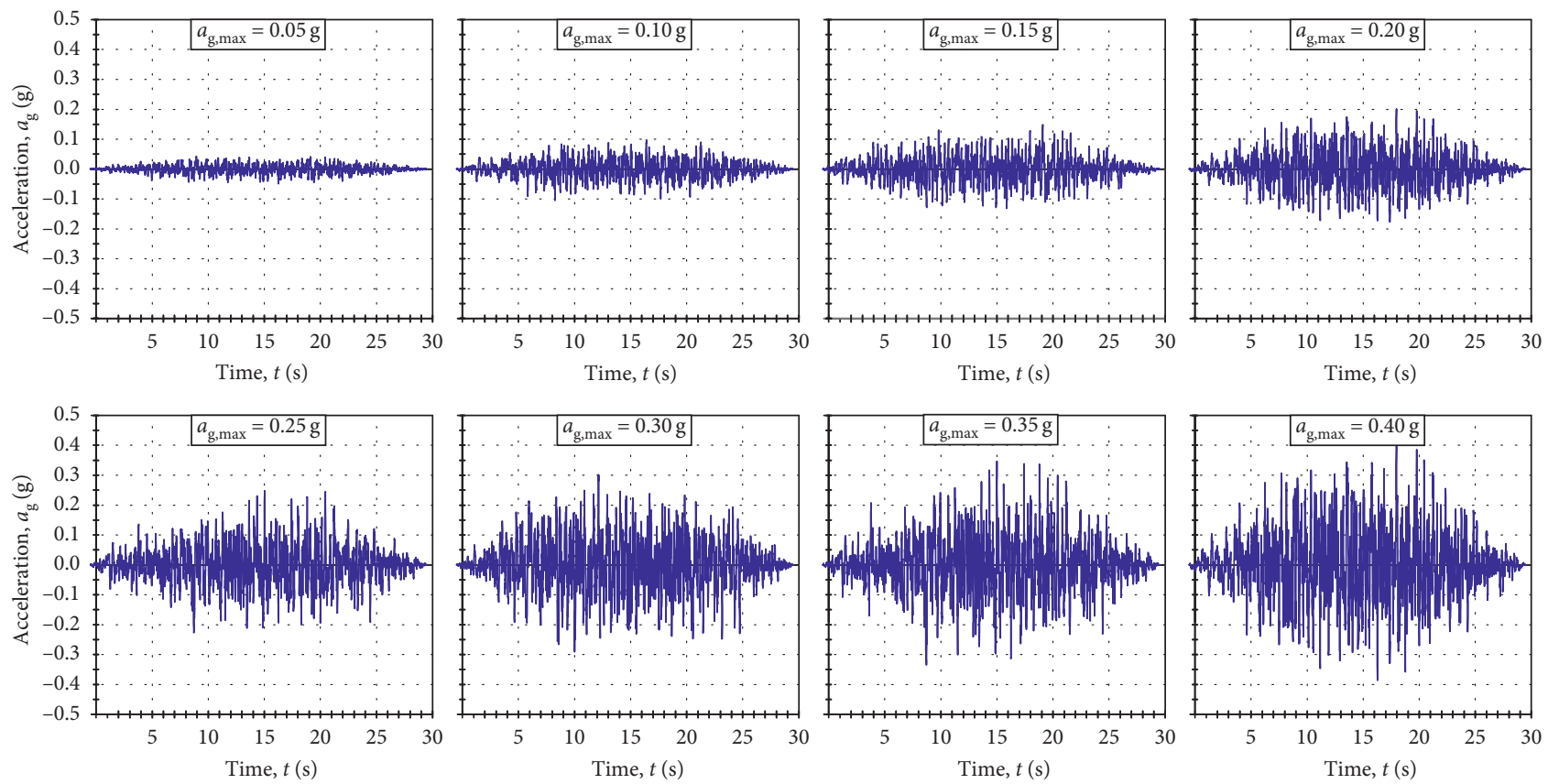

(b)

Figure 3: Applied horizontal base accelerations. (a) Elastic response spectra. (b) Artificial accelerograms.

[17]. The maximum acceleration for the first excitation was $a_{\mathrm{g}, \max }=0.05 \mathrm{~g}$ and, for the subsequent excitations, was successively increased by $0.05 \mathrm{~g}$.

Characteristic displacements, accelerations, and strains of the structure (Figure 4) were measured for each excitation. Note that the measured tensile concrete strains may contain the impact of the eventual formed concrete cracks in the measuring zone and that the strains of the steel rebar can be determined by the position of cracks in the concrete in the measuring zone. The measured values for some applied excitations are presented hereinafter, and a detailed presentation of the equipment used in the study can be found in $[18,19]$.

Horizontal displacement of the top of the column is presented in Figure 5. Column C1 already had a significant irreversible displacement of the top of approximately $10 \mathrm{~mm}$ after excitation with $a_{\mathrm{g}, \max }=0.2 \mathrm{~g}$. At $a_{\mathrm{g}, \max }=0.3 \mathrm{~g}$, the top of column $\mathrm{C} 1$ had an irreversible displacement of approximately $55 \mathrm{~mm}$. The tops of columns C2 and C3 had a small irreversible displacement at this excitation. At $a_{\mathrm{g}, \max }=0.3 \mathrm{~g}$, the top of column $\mathrm{C} 2$ had an irreversible displacement of approximately $20 \mathrm{~mm}$, and the top of the column C3 of about $6 \mathrm{~mm}$. Column C1 collapsed under excitation with $a_{\mathrm{g}, \max }=0.35 \mathrm{~g}$. The top of column C3 had a greater displacement at $a_{\mathrm{g}, \max }=0.35 \mathrm{~g}$ than that at the top of column $\mathrm{C} 2$. At the excitation with $a_{\mathrm{g}, \max }=0.4 \mathrm{~g}$, columns C2 and C3 collapsed.

Vertical displacement of the top of the foundation is shown in Figure 6. Column C1 was fixed to the surface of the shake table, and its foundation had no vertical movement. 


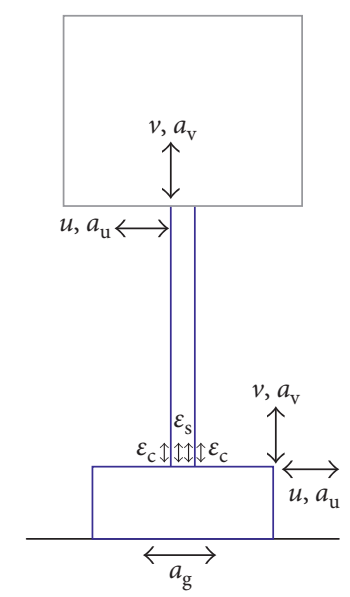

$u$ : horizontal displacement

$v$ : vertical displacement

$a_{\mathrm{u}}:$ horizontal acceleration

$a_{\mathrm{v}}$ : vertical acceleration

$\varepsilon_{\mathrm{c}}$ : concrete strain

$\varepsilon_{s}:$ reinforcement strain

$a_{\mathrm{g}}$ : shake table acceleration

Figure 4: Measured values.

As a result of compaction of the limestone sand below the foundation, after excitations with higher accelerations, foundations of columns C2 and C3 had a permanent settlement. The column C3 with the thick layer of sand had a significantly greater settlement. After compaction of the limestone sand under the foundation of column C3 under repeated excitations, vertical displacement of foundation was consolidated. The foundation of column C3 had a greater uplifting than the foundation of column $\mathrm{C} 2$.

The reinforcement strain at the bottom of the column on its left side for some excitations is shown in Figure 7. At the excitation with $a_{\mathrm{g} \text {, } \max }=0.2 \mathrm{~g}$, column C2 had a high tensile strain in the reinforcement (approximately 8\%o), which caused yielding of the steel rebar. At the end of this excitation, the tensile strain in the reinforcement remained irreversible for approximately 4\%o. During this excitation, no irreversible tensile strain in columns $\mathrm{C} 1$ and C3 occurred. At $a_{\mathrm{g}, \max }=0.3 \mathrm{~g}$, column $\mathrm{C} 1$ had irreversible tensile strain in the reinforcement of approximately $2.5 \%$, while irreversible strain in the reinforcement of column C3 did not occur. At $a_{\mathrm{g}, \max }=0.35 \mathrm{~g}$, column C2 had a high tensile strain in the reinforcement (approximately 22.0\%o), which remained irreversible for approximately $6.0 \%$ at the end of the excitation. At $a_{\mathrm{g}, \max }=$ $0.35 \mathrm{~g}$, column C1 collapsed, with irreversible tensile strain in reinforcement of approximately $2.0 \%$ only. Columns C2 and C3 collapsed under excitation with $a_{\mathrm{g}, \max }=0.4 \mathrm{~g}$. Thus, the irreversible tensile strain in the reinforcement of the column C2 was approximately $7.5 \%$ and that in the reinforcement of the column C3 was only approximately $1.0 \%$. It is obvious that the tensile strain in the reinforcement on the left side of column C3 was lower than the tensile strain in the same reinforcement of columns $\mathrm{C} 1$ and $\mathrm{C} 2$.

Reinforcement strain at the bottom of the column on its right side for some excitations is shown in Figure 8. At $a_{\mathrm{g}, \max }=0.2 \mathrm{~g}$, the irreversible tensile strain in the reinforcement of column C1 was approximately 3.0\%o and that of column C2 was approximately 2.0\%o. Irreversible strain in the reinforcement of column $\mathrm{C} 3$ did not occur. At the excitation with $a_{\mathrm{g}, \max }=0.3 \mathrm{~g}$, the tensile strain in the reinforcement of column C2 reached $15.0 \%$, with irreversible tensile strain of approximately $5.0 \%$ at the end of the excitation. Small irreversible tensile strain in the reinforcement of column $\mathrm{C} 1$ occurred at the end of this excitation. At $a_{\mathrm{g}, \max }=0.35 \mathrm{~g}$, column C1 collapsed with irreversible tensile strain in reinforcement of only approximately $2.0 \%$. At the excitation with $a_{\mathrm{g} \text {,max }}=0.4 \mathrm{~g}$, the irreversible tensile strain in the reinforcement of the column C3 was about approximately $4.0 \%$, while maximal compression strain in the reinforcement of the column $\mathrm{C} 2$ was approximately $-9.0 \%$.

The concrete strain at the bottom of the column at its left side is shown in Figure 9. Only concrete compressive strain is discussed below. At $a_{\mathrm{g}, \max }=0.2 \mathrm{~g}$, the compressive strain in the concrete of column C2 was close to $-4.0 \%$; that is, the concrete was close to being crushed. The compressive strain in the concrete of columns C1 and C3 was smaller.

The concrete strain at the bottom of the column at its right side is shown in Figure 10. The compressive strain is discussed below. At $a_{\mathrm{g}, \max }=0.2 \mathrm{~g}$, the compressive strain in the concrete of column $\mathrm{C} 1$ was close to $-2.5 \%$ and that for columns $\mathrm{C} 2$ and $\mathrm{C} 3$ were smaller. At $a_{\mathrm{g}, \max }=0.3 \mathrm{~g}$, the compressive strain in the concrete of column $\mathrm{C} 1$ was over $-5.0 \%$ and failure of the strain gauge occurred. The concrete of this column was very close to being crushed. At $a_{\mathrm{g}, \max }=0.3 \mathrm{~g}$, the concrete of column C3 reached a compressive strain of approximately $-3.0 \%$.

Horizontal acceleration of the column top $\left(a_{\mathrm{u}}\right)$ is shown in Figure 11. The maximal horizontal accelerations of the top of all the columns were approximately equal. The valorization of the above values should be carefully done because the higher acceleration value does not mean at the same time greater stress in the structure. Namely, the strain sizes shown in Figures $7-10$ are more relevant for describing the stress levels in the construction.

The first period of free oscillation of the columns $\left(T_{1}\right)$ after the end of each successive base excitation was experimentally determined, at the maximum base acceleration $a_{\mathrm{g}}$, max, as shown in Figure 12(a), and the stiffness value of each column was calculated according to the following simplified expression as shown Figure 12(b):

$$
k=m \frac{4 \pi^{2}}{T^{2}} .
$$

The columns had almost equal values of $T_{1}$ which were approximately $T_{1}=0.64 \mathrm{~s}$ before starting the test, from which it follows that the layer of limestone sand below the foundation had no practical effect on the initial dynamic characteristics of the coupled system. After the first base excitation with $a_{\mathrm{g}, \max }=0.05 \mathrm{~g}$, an almost equal decrease in stiffness of all the columns occurred due to the appearance of plastic strains, which resulted in an increase of $T_{1}$. The stiffness of the columns decreased after the end of each successive base excitation, and $T_{1}$ increased. Before the 

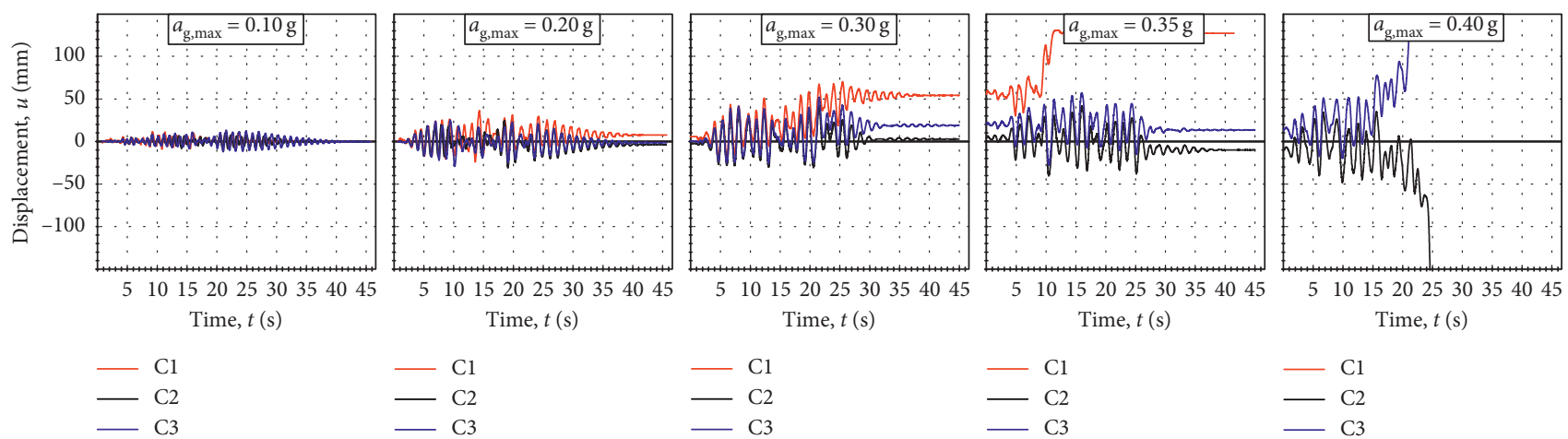

FIGURE 5: Horizontal displacement of the top of the column.
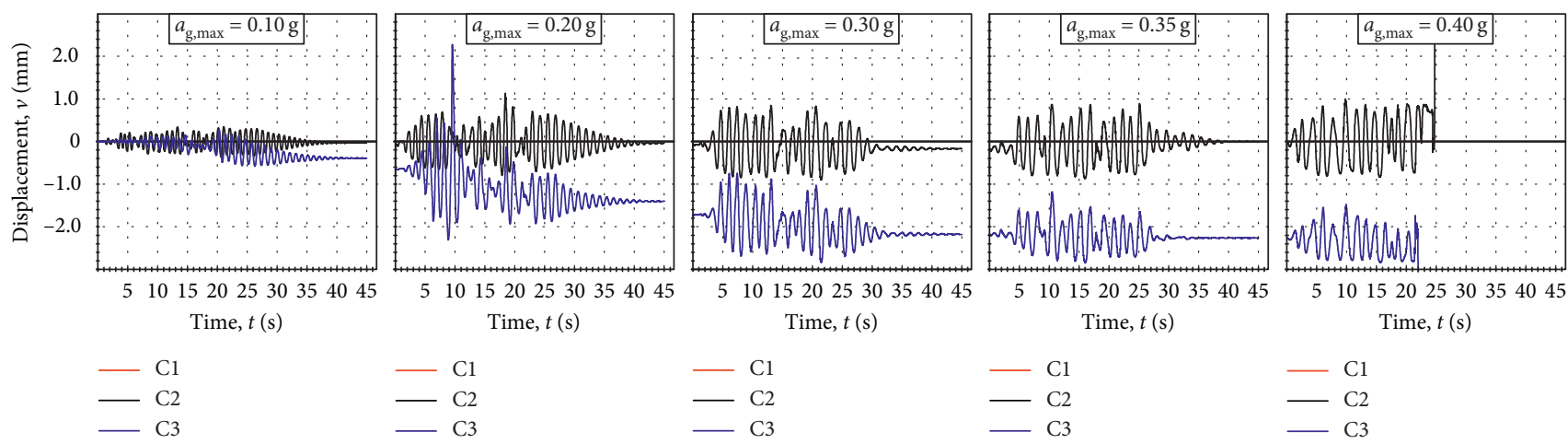

FIgURE 6: Vertical displacement of the top of the foundation on the left edge.
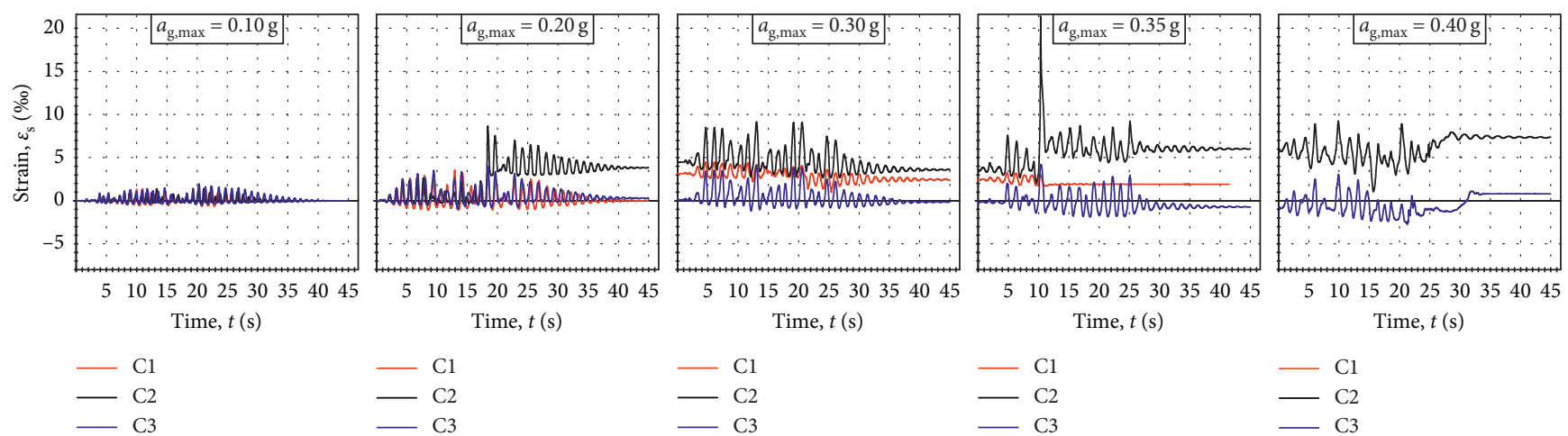

Figure 7: Reinforcement strain at the bottom of the column on the left side.

collapse of the columns, $T_{1}$ was approximately two times higher than before the application of the first base excitation. Thus, column $\mathrm{C} 1$ had a slightly higher decrease in stiffness up to $a_{\mathrm{g}, \max }=0.3 \mathrm{~g}$, whereas columns C2 and C3 had approximately equal decreases in stiffness.

The tested columns clearly exhibited different behaviors under the applied excitations and exhibited different mechanisms of the collapse. The column C1 collapsed under excitation with $a_{\mathrm{g}, \max }=0.35 \mathrm{~g}$; that is, it had the lowest bearing capacity. Columns C2 and C3 collapsed under excitation with $a_{\mathrm{g}, \max }=0.4 \mathrm{~g}$, with column C3 having the most favorable behavior during the previous excitations. Namely, the column $\mathrm{C} 3$ had a minimum reinforcement and concrete strain/stress (Figures 7-10) and maximum remaining stiffness (Figure 12).

Because of the small number of experiments in the presented study, it is not possible to make more precise conclusions regarding the thickness of the sand layer that could achieve the highest ultimate bearing capacity of the column. Extensive research studies on this problem based on the shake table are planned, which would include variation of the type of structure (rigid, stiff, and soft), the natural 

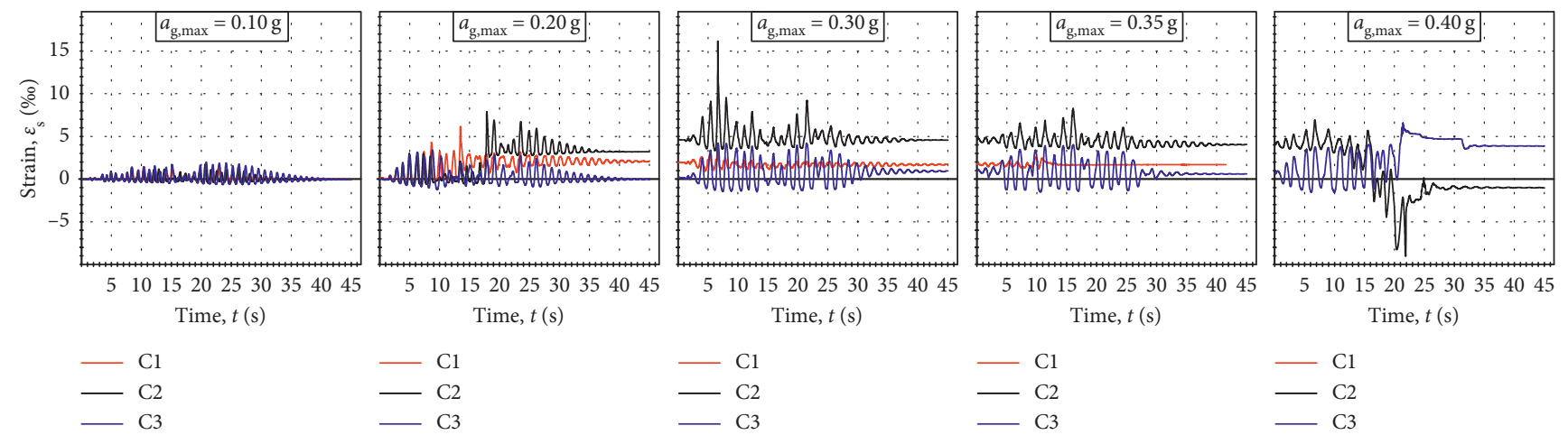

FIgURE 8: Reinforcement strain at the bottom of the column on the right side.
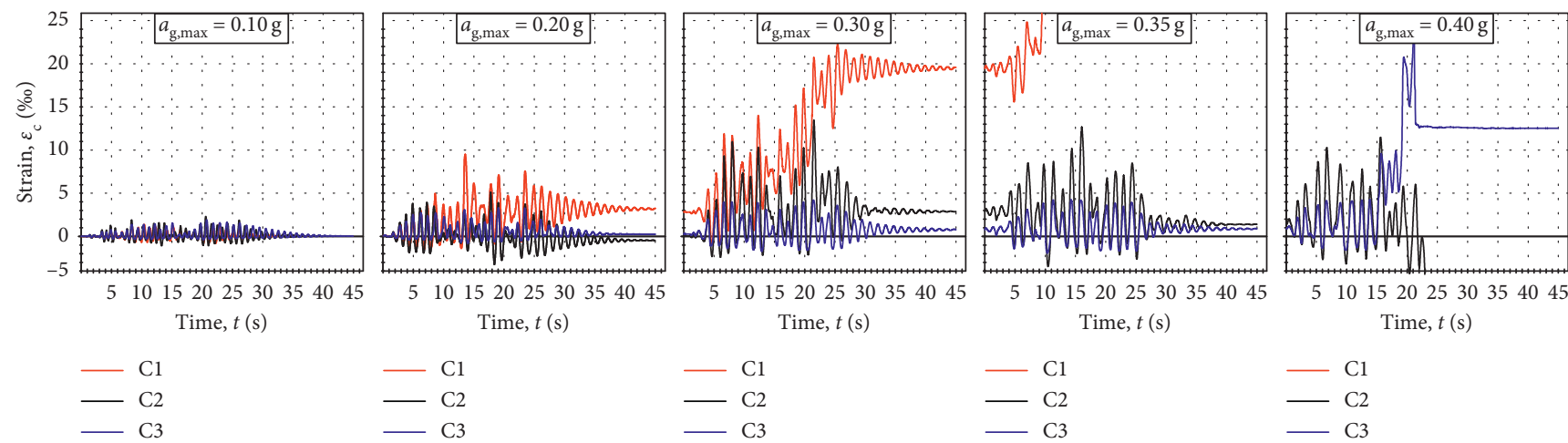

Figure 9: Concrete strain at the bottom of the column on the left side.
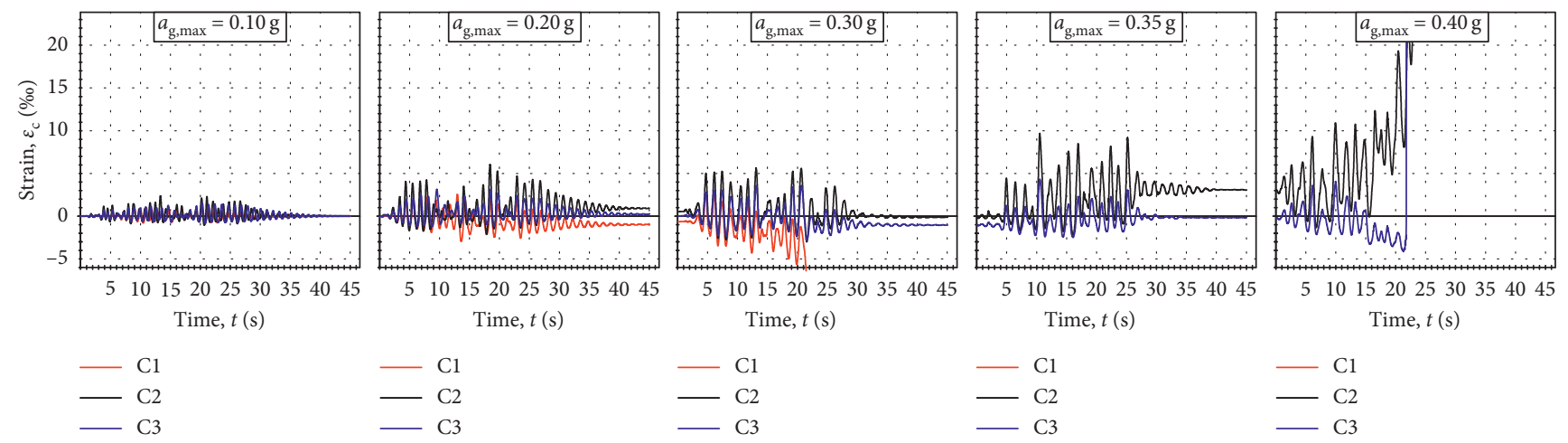

FIGURE 10: Concrete strain at the bottom of the column on the right side.

materials under the foundation (limestone sand, stone pebbles, etc.), the thickness and compaction of the layer, and the dominant frequencies of the base excitation.

\section{Numerical Modeling of the Performed Experimental Test}

The results of the performed experimental test presented in Section 2 can be simulated using a previously developed numerical model for static and dynamic analysis of planar concrete structures [19-23]. The model is briefly described hereinafter.
The adopted numerical model is quite simple, but it can simulate the primary material and geometric nonlinear effects of the concrete structures in contact with the ground. The model is primarily intended for practical use. The graphical interpretation of the adopted model is shown in Figure 13.

The model is based on the finite element method for spatial discretization of the soil-foundation-structure coupled system and on the finite difference method for the time integration of the equations of motion. Basic 8-node serendipity finite elements are used. 6-node planar and 2-node bar elements are adopted for contact elements (Figure 13(a)). 

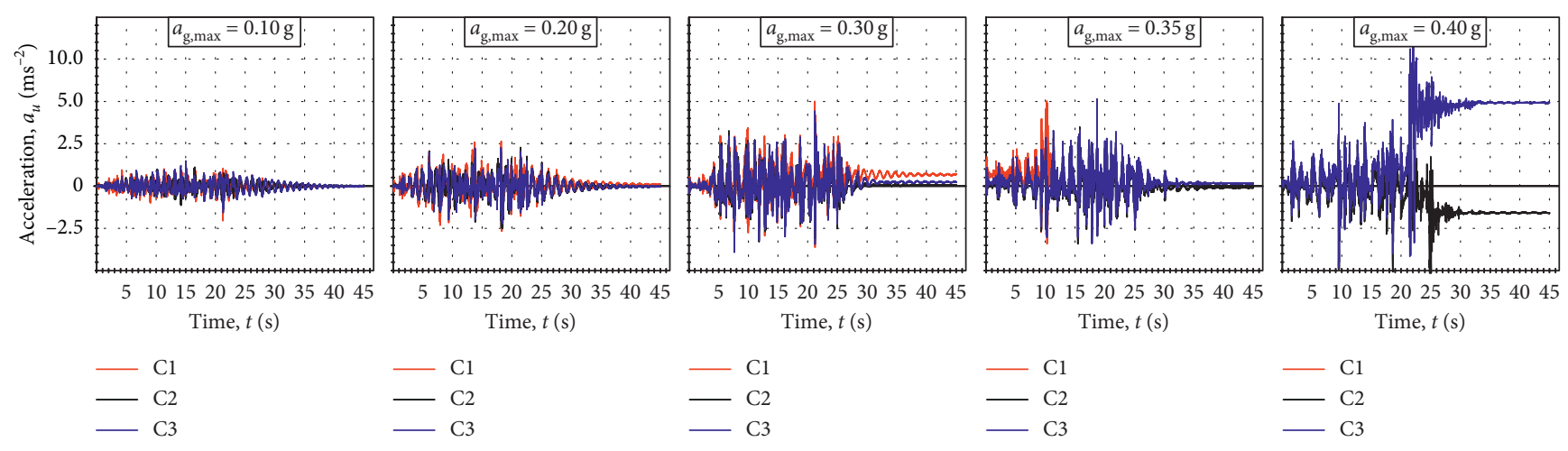

Figure 11: Horizontal acceleration of the column top.

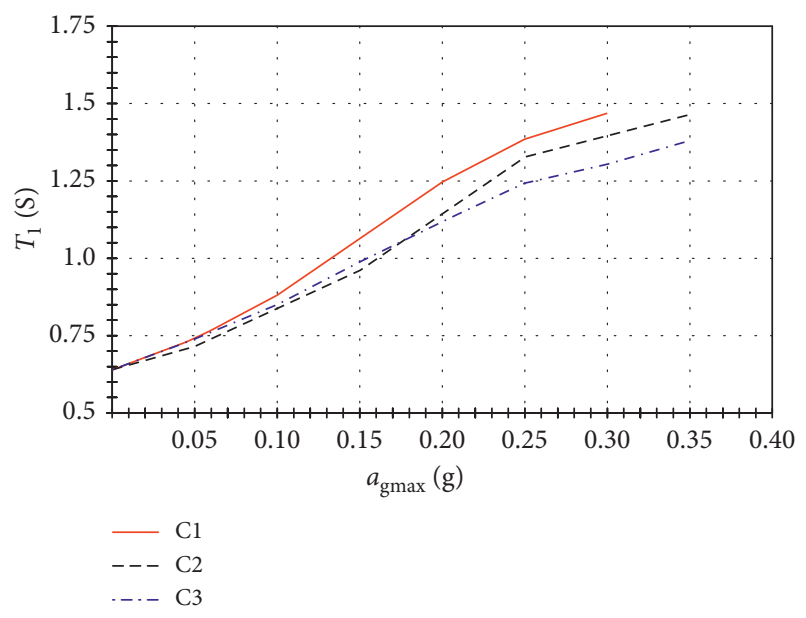

(a)

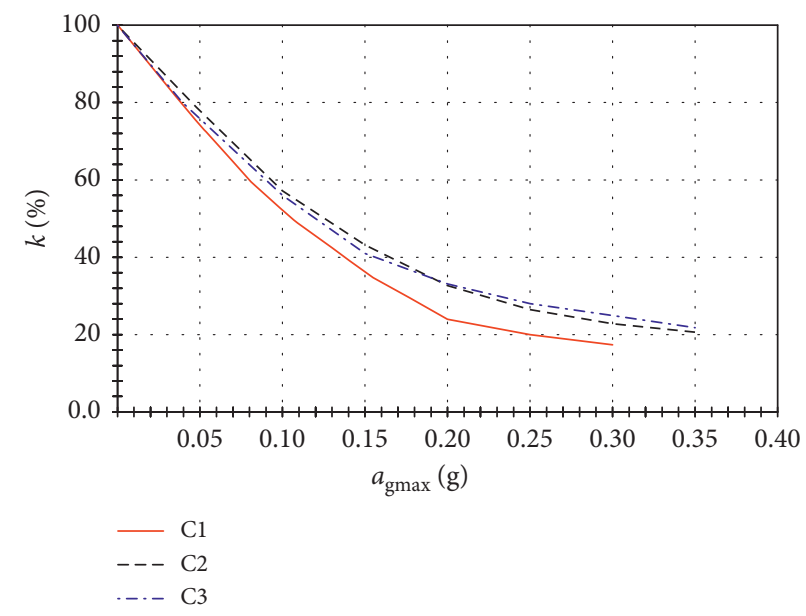

(b)

FiguRE 12: (a) First period of free oscillation of the columns determined after the end of each base excitation. (b) Normalized stiffness of the columns after the end of each successive base excitation.

To include the effects of large displacements, updated Lagrange formulation is used. Convergence criterion of incremental-iterative procedure is given as a function of current displacements' increment in relation to total displacements.

Biaxial failure of planar steel structures is modeled by the influence of normal stresses only. A classical elastic-plastic model for steel is used, with linear behavior in unloading (Figure 13(b)). Biaxial failure of planar steel structures is modeled by the effect of normal stresses only. Same behavior of steel in tension and compression is adopted. The von Mises yield criterion is used for steel yielding. The failure criterion of steel is defined as a function of principal strains, in an analogous way as a steel yielding.

The behavior of concrete in compression is described using an elastic-plastic theory (Figure 13(b)). The behavior of concrete in tension is described using an elastic-brittle model, including the modeling of cracks after the stresses reaching the maximal tensile concrete strength. The smeared crack model with fixed orthogonal cracks is adopted. The tensile stiffness of concrete between the cracks is simulated using a gradual reduction of the stiffness after the tensile stresses reaching the tensile strength of the concrete. The shear stiffness of the cracked concrete is simulated using gradual reduction of the shear modulus of the concrete as a function of the concrete strain perpendicular to the crack plane. Opening and closing of the cracks are also modeled.

The reinforcement is simulated using a one-dimensional curved bar element, within the basic concrete element. The full compatibility of the displacements between the concrete and the reinforcement is assumed. The behavior of the reinforcement steel is described by the polygonal stress-strain curve, with a linear behavior in unloading (Figure 13(b)). The influence of fatigue on the mechanical properties of concrete and steel related to the cyclic loading is not simulated. The simulation of the strain rate effects on the mechanical properties of concrete and steel due to the dynamic loading is enabled. Soil is simulated using a constitutive model of concrete, with adjustment of the associated material parameters. The constitutive model of the contact elements is described by the normal stress-normal strain polygonal curve and by the shear stress-shear strain polygonal curve (Figure 13(c)). The simulation of penetration, 


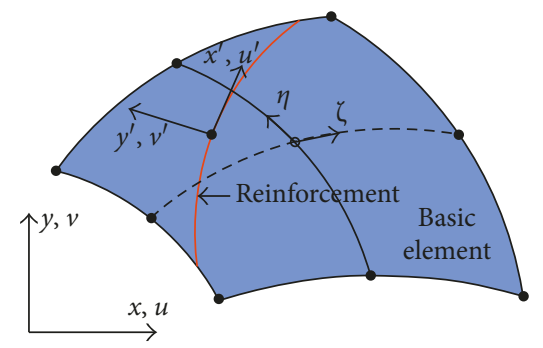

Basic 2D element

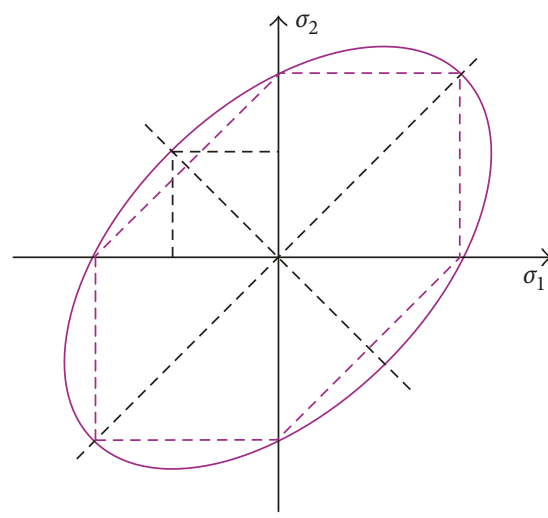

Structural steel

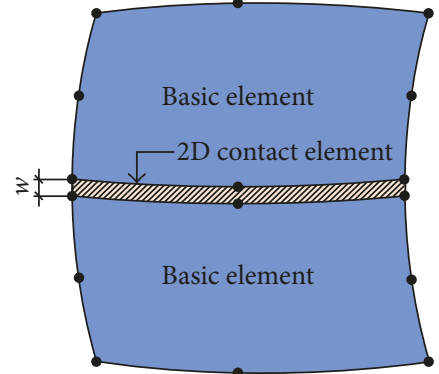

$2 \mathrm{D}$ contact element

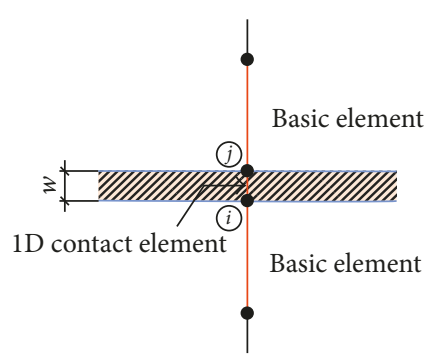

$1 \mathrm{D}$ contact element

(a)
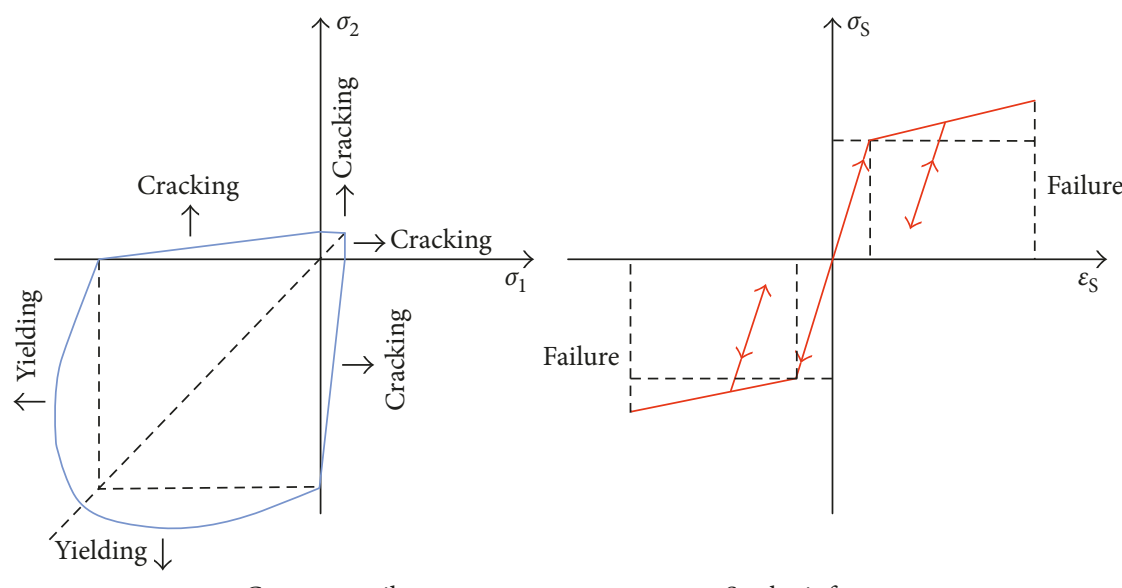

(b)

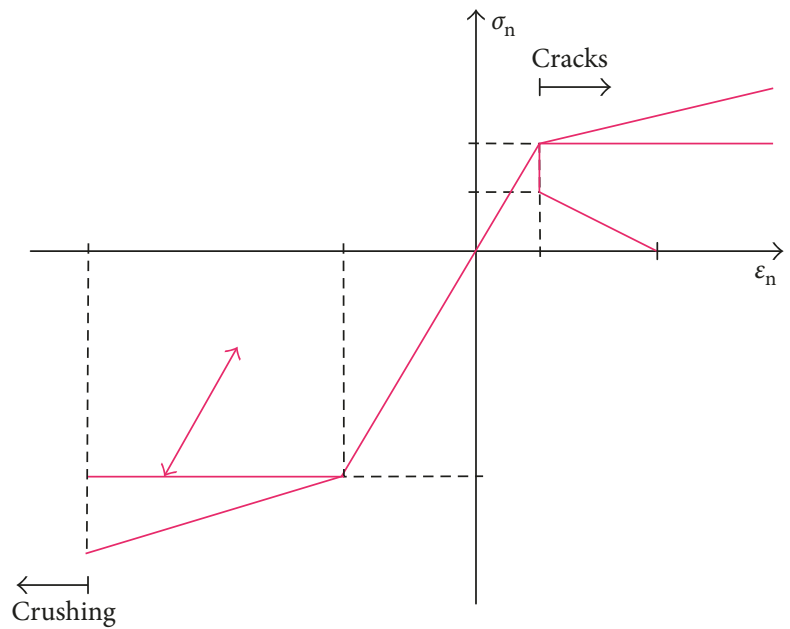

Transfer of normal stresses

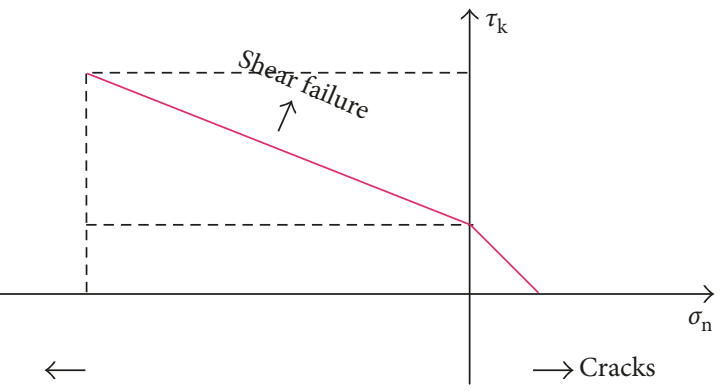

Failure in compression

Transfer of shear stresses

(c)

Figure 13: The graphical interpretation of the adopted model. (a) Adopted finite elements for a spatial discretization. (b) Adopted constitutive material models. (c) Constitutive models for contact elements.

separation, and sliding on the contact surface between the foundation and the soil is modeled.

Spatial discretization of tested column C3 is presented in Figure 14(a), and the shake table test model is shown in Figure 14(b). A comparison of some of the experimentally determined and numerically obtained results for column C3 is presented in Figure 15.
Generally, a relatively good agreement between the experimental and the numerical results was observed. During the excitations with lower levels of acceleration and a lower level of nonlinearity in the system, the best agreement between the experimental and numerical results was recorded. With an increase in the number of successive base excitations and an increase in the amplitude of the 


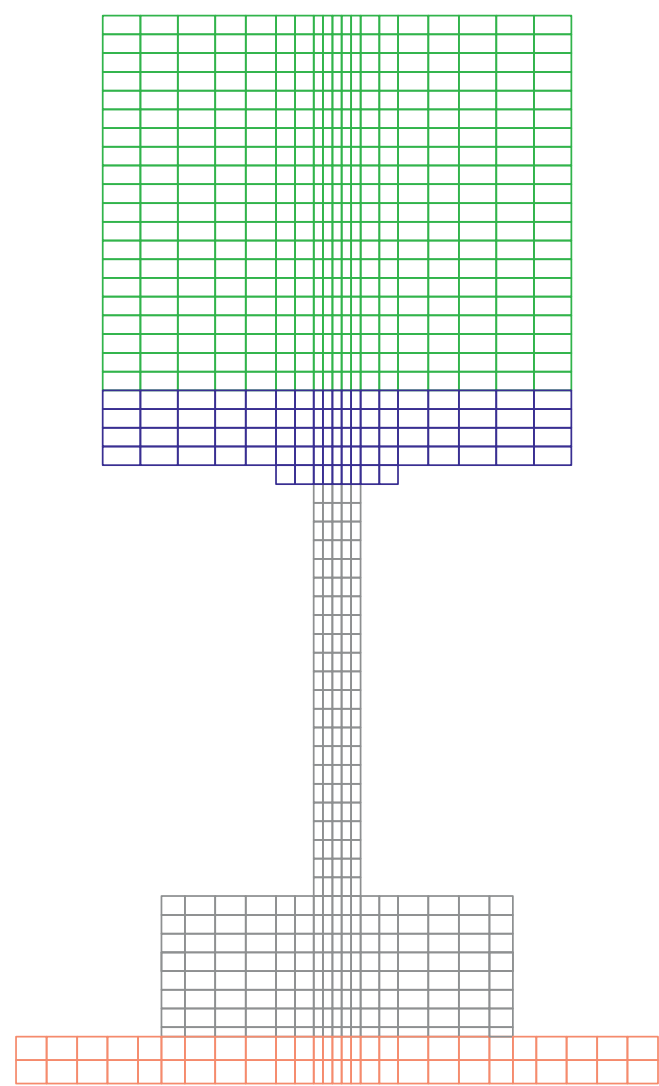

(a)

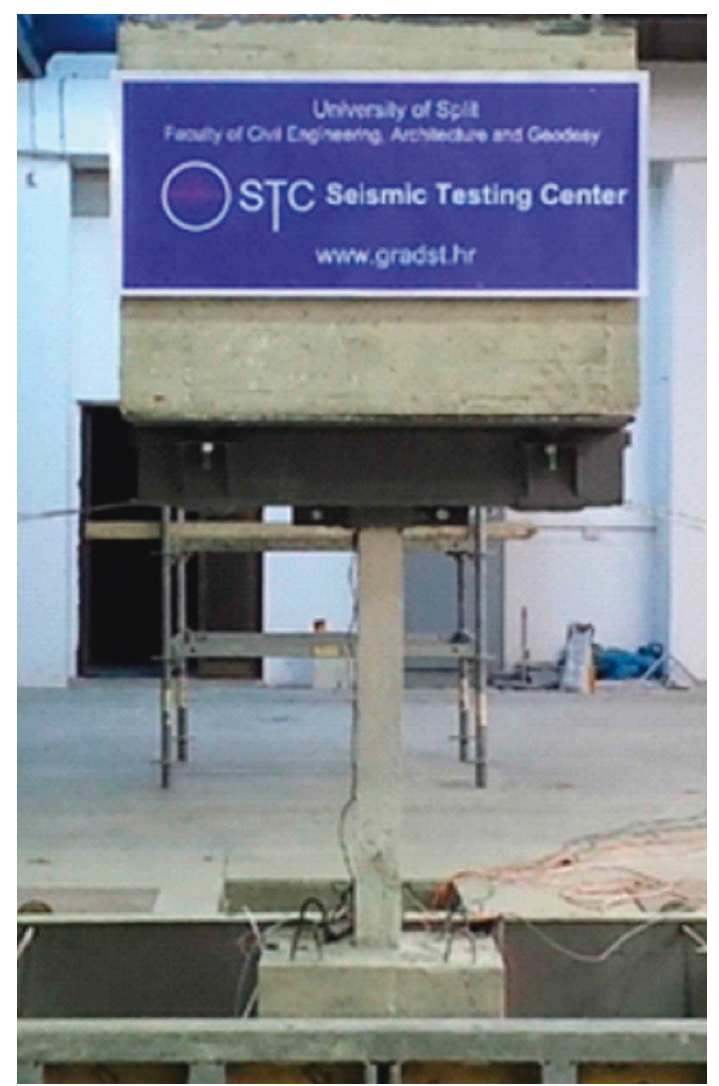

(b)

FIgURE 14: Tested column C3. (a) Spatial discretization. (b) Shake table test model.
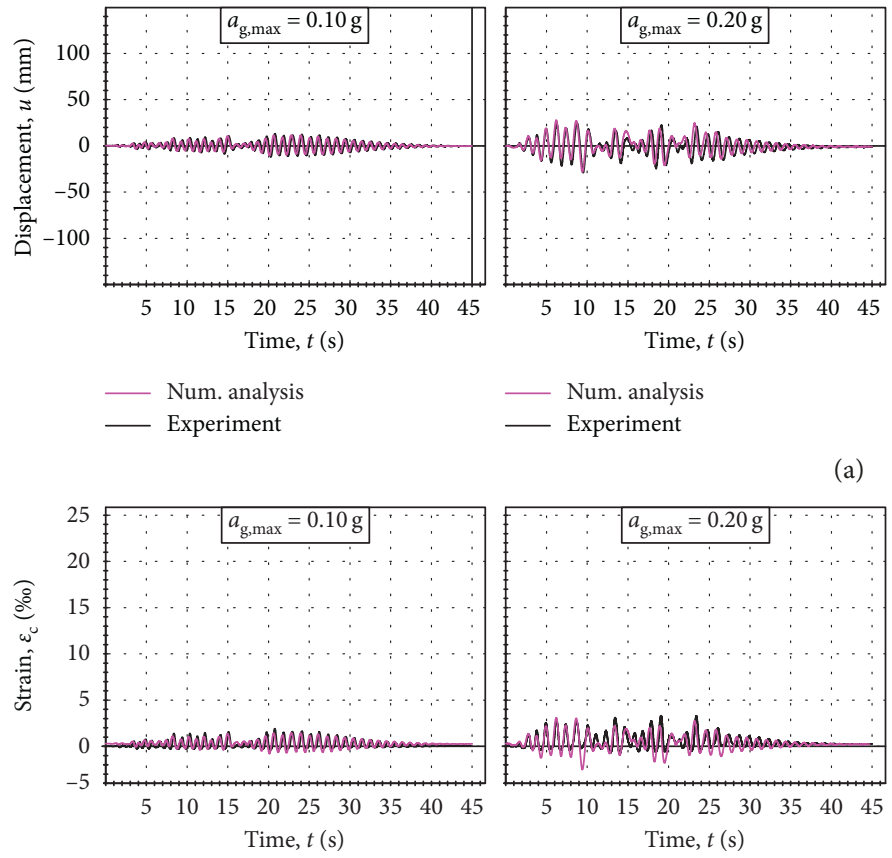

_ Num. analysis
_ Num. analysis

- Experiment

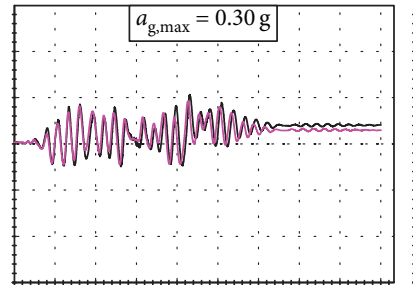

$\begin{array}{lllllllll}5 & 10 & 15 & 20 & 25 & 30 & 35 & 40 & 45\end{array}$ Time, $t(\mathrm{~s})$

_ Num. analysis

(a)

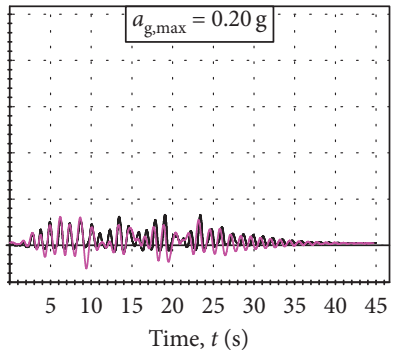

_ Num. analysis

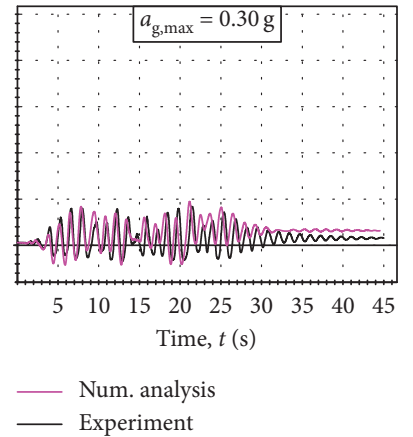

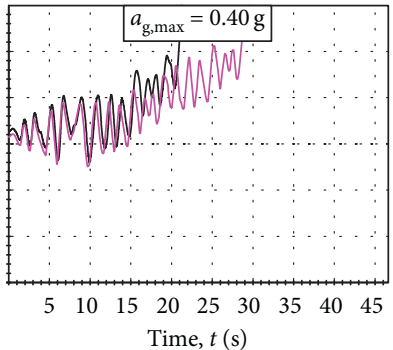

_ Num. analysis

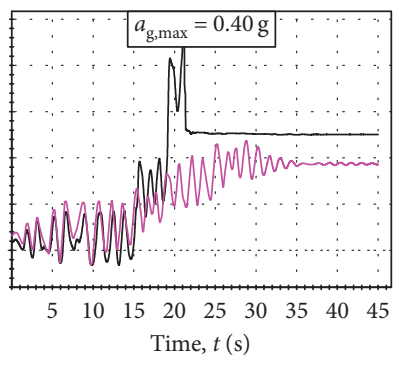

_ Num. analysis

_ Experiment

(b)

FIGURE 15: Comparison of some experimentally determined and numerically obtained results. (a) Horizontal displacement of the top of column C3. (b) Concrete strain at the bottom of column C3 on the left side. 
TABLE 1: Comparison of some maximum values of experimental and numerical results.

\begin{tabular}{|c|c|c|c|c|c|c|c|c|}
\hline & \multicolumn{2}{|c|}{$a_{\mathrm{g}, \max }=0.1 \mathrm{~g}$} & \multicolumn{2}{|c|}{$a_{\mathrm{g}, \max }=0.2 \mathrm{~g}$} & \multicolumn{2}{|c|}{$a_{\mathrm{g}, \max }=0.3 \mathrm{~g}$} & \multicolumn{2}{|c|}{$a_{\mathrm{g}, \max }=0.4 \mathrm{~g}$} \\
\hline & Experimental & Numerical & Experimental & Numerical & Experimental & Numerical & Experimental & Numerical \\
\hline $\begin{array}{l}\text { Column C1 } \\
u(\mathrm{~mm})\end{array}$ & 11.02 & 11.29 & 36.20 & 38.01 & 70.31 & 72.30 & - & - \\
\hline$v(\mathrm{~mm})$ & - & - & - & - & - & - & - & - \\
\hline$\varepsilon_{\mathrm{s}}$-left side $(\% o)$ & 1.69 & 1.77 & 3.56 & 3.42 & 4.48 & 4.53 & - & - \\
\hline$\varepsilon_{\mathrm{c}}$-right side $(\%)$ & -0.92 & -0.94 & -2.53 & -2.62 & -5.52 & -5.47 & - & - \\
\hline$a_{\mathrm{u}}\left(\mathrm{ms}^{-2}\right)$ & 2.01 & 1.98 & 2.52 & 2.61 & 5.06 & 4.99 & - & - \\
\hline $\begin{array}{l}\text { Column C2 } \\
u(\mathrm{~mm})\end{array}$ & 10.05 & 10.45 & 31.11 & 30.98 & 43.12 & 42.98 & 76.31 & 73.42 \\
\hline$v(\mathrm{~mm})$ & 0.34 & 0.35 & 1.13 & 1.21 & 0.82 & 0.79 & 1.08 & 1.06 \\
\hline$\varepsilon_{\mathrm{s}}$-left side $(\% o)$ & 1.38 & 1.45 & 8.65 & 8.77 & 9.06 & 8.99 & 9.24 & 9.35 \\
\hline $\mathcal{E}_{\mathrm{c}}$-right side $(\% \mathrm{o})$ & -1.05 & -1.16 & -2.12 & -2.08 & -3.15 & -3.26 & -1.35 & -1.29 \\
\hline$a_{\mathrm{u}}\left(\mathrm{ms}^{-2}\right)$ & 1.12 & 1.18 & 2.51 & 2.42 & 3.28 & 3.48 & 5.06 & 4.99 \\
\hline Column C3 & & & & & & & & \\
\hline$u(\mathrm{~mm})$ & 13.06 & 13.51 & 29.12 & 28.55 & 52.22 & 49.11 & 96.57 & 105.2 \\
\hline$v(\mathrm{~mm})$ & 0.58 & 0.63 & 2.27 & 2.12 & 2.84 & 2.95 & 2.84 & 2.96 \\
\hline $\mathcal{E}_{\mathrm{s}}$-left side $(\% o)$ & 1.94 & 1.88 & 4.00 & 3.95 & 4.08 & 3.98 & 3.00 & 2.95 \\
\hline$\varepsilon_{\mathrm{c}}$-right side $(\% 0)$ & -0.82 & -0.86 & -1.22 & -1.32 & -3.05 & -3.11 & -4.15 & -4.00 \\
\hline$a_{\mathrm{u}}\left(\mathrm{ms}^{-2}\right)$ & 1.51 & 1.62 & 2.25 & 2.02 & 4.42 & 4.51 & 12.54 & 11.28 \\
\hline
\end{tabular}

acceleration, significant nonlinearities (including plastic deformation) in the system were found to occur, which result in certain disagreements between the experimental and numerical results. Disagreements are the consequences of the shortcomings of the constitutive models, the spatial and temporal discretization, the convergence criteria, and some other influential parameters. Numerical simulations are also made for columns C1 and C2. A comparison of some maximum experimentally determined and numerically obtained results for columns $\mathrm{C} 1, \mathrm{C} 2$, and C3 are presented in Table 1. Generally, a relatively good agreement between the experimental and the numerical results was observed.

\section{Conclusions}

Unfortunately, to date, no devices exist for seismic isolation of structures that can comply with the numerous requirements that must be satisfied for their wide application in practice. The placement of a layer of appropriate natural materials under the foundation can be an optimal solution for seismic base isolation for many structures, especially in less-developed parts of the world [14-16]. Such materials should retain all of their mechanical characteristics over the projected life of the building.

The results of experimental research presented in this paper shows that the application of a layer of classical stone sand below the foundation can serve as a means of highquality seismic isolation for rigid construction. In the performed small-scale shake table tests, a cantilever concrete column with a fixed foundation on the shake table had lower ultimate bearing capacity than the same column with the layers of limestone sand below its foundation. Therefore, the layer of limestone sand below the foundation increases the safety of the column under earthquake loading. Herein, it is necessary to adopt the appropriate thickness and compaction of this layer. In the performed tests, the $100 \mathrm{~mm}$ thick layer of limestone sand was more efficient than the $20 \mathrm{~mm}$ thick layer. Namely, the C3 column based on the $100 \mathrm{~mm}$ thick layer of limestone sand, for maximum base acceleration, had the lowest strain/stress in the structure and the highest residual stiffness, that is, the highest safety. Here, note that the layers were slightly compacted. For the layers made of the same material, its thickness and compactness have a great influence on the seismic response of the structure. Because of the small number of experiments in the present study, it is not possible to make more precise conclusions regarding the reliable effects of the sand layer below the foundation on the decrease in the seismic forces in the structure. Therefore, more extensive experimental studies of seismic base isolation using different natural materials below a foundation of different types of structures are planned.

The presented numerical model for static and dynamic analysis of planar concrete structures coupled with soil, which can simulate the primary nonlinear effects of the system, was verified based on the results of previously performed experimental shake table tests. Good agreement of numerical and experimental results confirms that the presented numerical model may find use in practical application. However, further verification of the model is required.

\section{Data Availability}

All data underlying the findings of the study are presented in this article.

\section{Conflicts of Interest}

The authors declare that there are no conflicts of interest regarding the publication of this paper. 


\section{Acknowledgments}

The research and publication of this paper was funded by authors.

\section{References}

[1] G. E. Christenson, "Earthquake Ground Shaking in Utah," in Utah Geological Survey Public Information Series, Utah Geological Survey, Salt lake city, UT, USA, 1994.

[2] A. K. Chopra, Dynamics of Structures: Theory and Applications to Earthquake Engineering, Pearson Prentice Hall, Upper Saddle River, NJ, USA, 2007.

[3] C. M. Chang and B. F. Spencer, "Active base isolation of buildings subjected to seismic excitations," Earthquake Engineering and Structural Dynamics, vol. 39, no. 13, pp. 1493-1512, 2010.

[4] M. Eatherton, X. Ma, H. Krawinkler et al., "Design concepts for controlled rocking of self-centering steel-braced frames," Journal of Structural Engineering, vol. 140, no. 11, article 04014082, 2014.

[5] J. M. Kelly, "Aseismic base isolation: review and bibliography," Soil Dynamics and Earthquake Engineering, vol. 5, no. 4, pp. 202-216, 1986.

[6] F. Naiem and J. M. Kelly, Design of Seismic Isolated Structures: From Theory to Practice, John Willey \& Sons, Inc., Hoboken, NJ, USA, 1999.

[7] J. Stanton and C. Roeder, "Advantages and limitations of seismic isolation," Earthquake Spectra, vol. 7, no. 2, pp. 301323, 1991.

[8] L. Tashkov, K. Manova, L. Krstevska, and M. Garevski, "Evaluation of efficiency of ALSC floating-sliding baseisolation system based on shake table test and floor response spectra," Bulletin of Earthquake Engineering, vol. 8, no. 4, pp. 995-1018, 2010.

[9] T.A. Morgan and S.A. Mahin, "The use of base isolation systems to achieve complex seismic performance objectives," PEER Report No. 2011/06, Pacific Earthquake Engineering Research Center, University of California, Berkeley, CA, USA, 2011.

[10] G. P. Warn and K. L. Ryan, "A review of seismic isolation for buildings: historical development and research needs," Buildings, vol. 2, no. 3, pp. 300-325, 2012.

[11] W. Xiong and Y. Li, "Seismic isolation using granulated tire-soil mixtures for less-developed regions: experimental validation," Earthquake Engineering and Structural Dynamics, vol. 42, pp. 2187-2193, 2013.

[12] H. H. Tsang, S. H. Lo, X. Xu, and S. M. Neaz, "Seismic isolation for low-to-medium-rise buildings using granulated rubber-soil mixtures: numerical study," Earthquake Engineering and Structural Dynamics, vol. 41, no. 14, pp. 20092024, 2013.

[13] C. Haselton, J. Baker, A. Lied, and G. Deierlein, “Accounting for ground-motion spectral shape characteristics in structural collapse assessment through an adjustment for epsilon," Journal of Structural Engineering, vol. 137, no. 3, pp. 332-344, 2011.

[14] M. K. Yegian and U. Kadakkal, "Foundation isolation for seismic protection using a smooth synthetic liner," Journal of Geotechnical and Geo-Environmental Engineering, vol. 130, no. 11, pp. 1121-1130, 2004.

[15] S. J. Patil, G. R. Reddy, R. Shivshankar, R. Babu, B. R. Jayalekshmi, and B. Kumar, "Natural base isolation of structures having raft foundations," International Journal of
Emerging Technology and Advanced Engineering, vol. 2, no. 8, pp. 23-38, 2012.

[16] S. J. Patil, G. R. Reddy, R. Shivshankar et al., "Seismic base isolation for structures using river sand," Earthquakes and Structures, vol. 10, no. 4, pp. 829-847, 2016.

[17] http://dicata.ing.unibs.it/gelfi/software/simqke.

[18] J. Radnić, N. Grgić, D. Matešan, and G. Baloević, "Shake table testing of reinforced concrete columns with different layout size of foundation," Material Science and Engineering Technology, vol. 46, no. 4-5, pp. 348-367, 2015.

[19] N. Grgić, Experimental testing and numerical modeling of slender reinforced concrete columns under seismic conditions, Ph.D. thesis, University of Split, Split, Croatia, 2014.

[20] J. Radnić, A. Harapin, D. Matešan et al., "Numerical model for analysis of masonry structures," Gradjevinar, vol. 63, no. 6, pp. 529-546, 2011.

[21] N. Grgić, J. Radnić, D. Matešan, and A. Buzov, "Effect of mass on the behavior of concrete columns under seismic load," Material Science and Engineering Technology, vol. 47, no. 5-6, pp. 483-493, 2016.

[22] N. Grgić, J. Radnić, D. Matešan, and I. Banović, "Stirrups effect on the behavior of concrete columns during an earthquake," Material Science and Engineering Technology, vol. 48, no. 5, pp. 406-419, 2017.

[23] G. Baloević, J. Radnić, D. Matešan, N. Grgić, and I. Banović, "Comparison of developed numerical macro and micro masonry models for static and dynamic analysis of masonryinfilled steel frames," Latin American Journal of Solids and Structures, vol. 13, no. 12, pp. 2251-2265, 2016. 


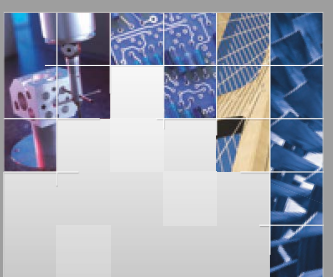

\section{Enfincering}
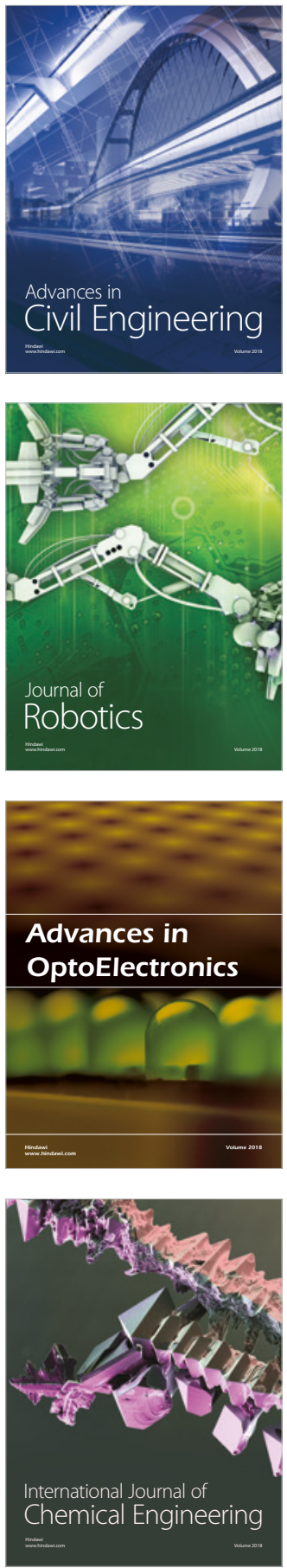

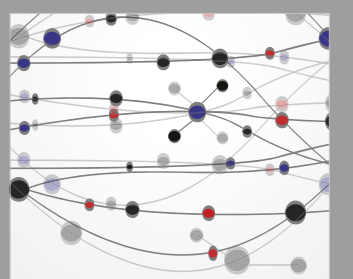

\section{Rotating \\ Machinery}

The Scientific World Journal

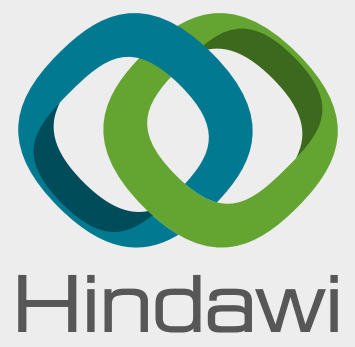

Submit your manuscripts at

www.hindawi.com
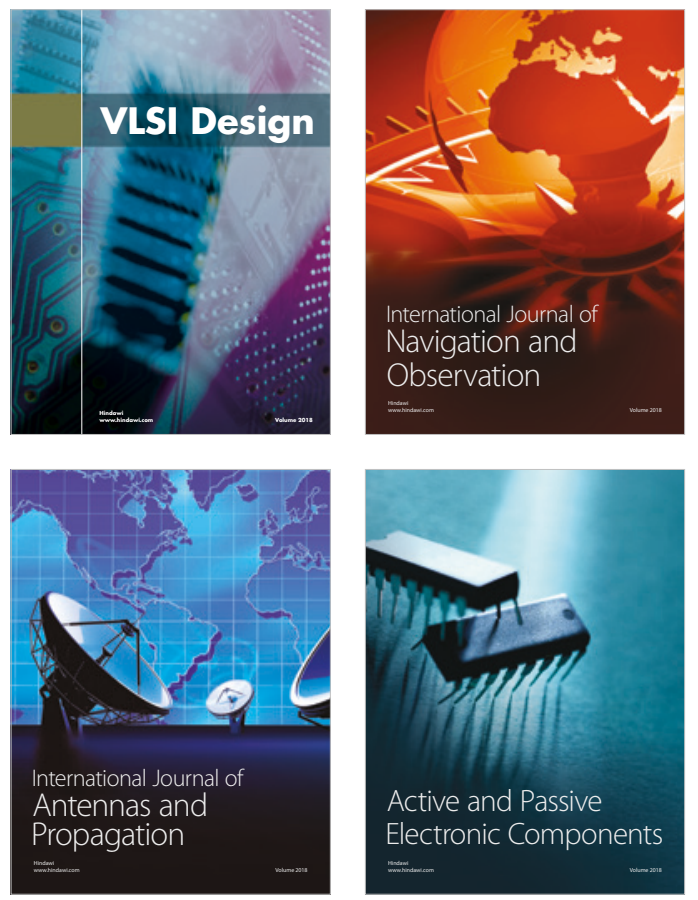
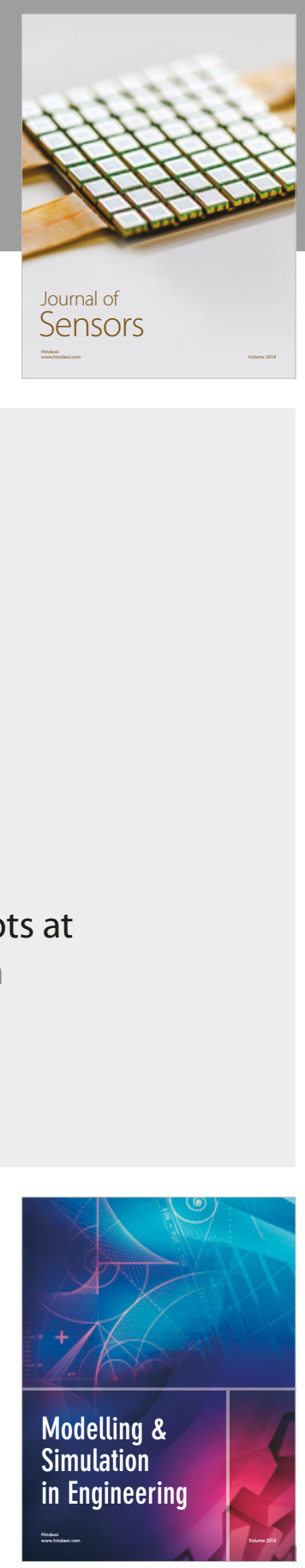

\section{Advances \\ Multimedia}
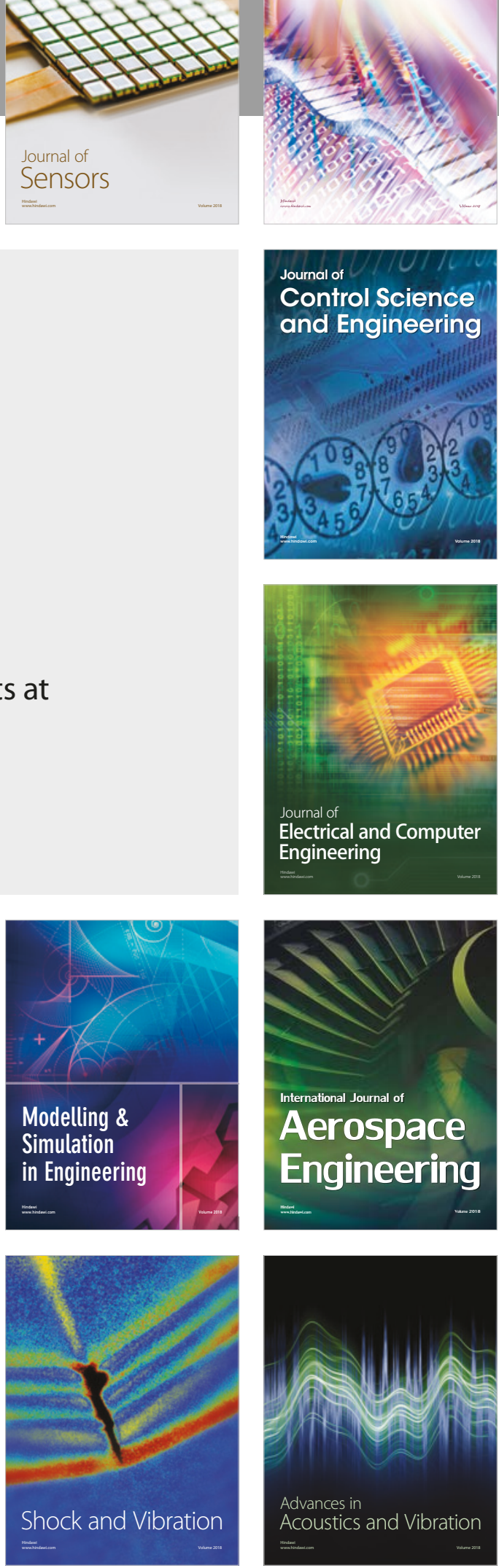